\title{
Ageism between Medical and Preliminary Medical Persons in Korea
}

\author{
Jiyeon Lee ${ }^{1}$, Hyeongseop $\mathrm{Yu}^{1}$, Hyun Hee $\mathrm{Cho}^{2}$, MinWoo Kim ${ }^{3}$, Seungrye Yang ${ }^{3}$ \\ ${ }^{1}$ Department of Geriatric Medicine, College of Medicine, The Catholic University of Korea, Seoul, Korea \\ ${ }^{2}$ Department of Geriatric Medicine, Eunpyeong St. Mary's Hospital, College of Medicine, The Catholic University of Korea, Seoul, Korea \\ ${ }^{3}$ Graduate School for Advanced Aging, Kyung Hee University, Yongin, Korea
}

Corresponding Author:

Hyun Hee Cho, MD, $\mathrm{PhD}$

Department of Geriatric Medicine,

Eunpyeong St. Mary's Hospital, 1021,

Tongil-ro, Eunpyeong-gu, Seoul 03312,

Korea

E-mail: drrabbit@catholic.ac.kr

ORCID:

https://orcid.org/0000-0002-6688-5206

Received: November 25, 2019

Revised: March 11, 2020

Accepted: March 11, 2020
Background: We aimed to analyse the trends in ageism among health care providers and medical students in the Republic of Korea. Methods: We used the Fraboni Scale of Ageism (FSA), Relating to Older People Evaluation (ROPE) questionnaire, Anxiety about Aging Scale (AAS), and the Facts on Aging Quiz II to assess ageism in medical students $(n=90)$, nurses $(n=114)$, and physicians ( $n=83$ ). We grouped health care providers based on the percentage of aged patients (over 65 years) that they treated. Results: Compared to the other groups, physicians had more knowledge about aging and the highest and lowest total scores in the FSA and ROPE, respectively. The total FSA scores were negatively correlated with the percentage of aged patients treated. Regarding the ROPE score, negative and positive ageist behaviors were positively correlated with the percentage of aged patients. Conclusions: Ageism and ageist behavior among physicians differed from previous reports and those of the other groups mentioned in the present study. Although physicians had more knowledge of aging, they had expressed a high levels of ageism. However, they did not act ageistically. Health care providers who treat a large number of older patients had minimal ageism but more ageist behavior. These findings indicate that continued education of geriatrics and ageism for medical staff and prospective medical personnel could help improve this situation.

Key Words: Ageism, Korea, Health personnel

\section{INTRODUCTION}

Butler") defined ageism or age discrimination as "Prejudice by one age group towards other age groups". Iversen et al. ${ }^{2}$ defined ageism as negative or positive stereotypes, prejudice, and/or discrimination against (or to the advantage of) people based on chronological age or a perception of a person as being "old", "too old", "young", or "too young”. Ageism should be treated like gender discrimination, racial discrimination, homosexual discrimination and discrimination against persons with disabilities because ageism results in differentiating, stratifying, and treating individuals differently based on attributes that they cannot change with effort or learning.

Ageistic behavior is an action resulting from ageism. For example, giving up one's seat to an older person and speaking loud to an older patient are considered positive ageistic behaviors. These ac- tions result from preconceptions that older people have weak legs and cannot hear properly. Omitting detailed medical explanations or saying that older individuals are okay are considered negative ageistic behaviors arising from an age-based prejudice that older people have poor cognitive skills.

Ageism and ageist behaviors can significantly affect health care. Medical professionals should offer health care to all patients equally and patients should not be discriminated under any circumstances based on sex, nationality, religion, ethnicity, sexual identity, or age. However, in practice, age has served as a benchmark for setting treatment policy. Older women with breast cancer have typically fewer opportunities to receive breast conservative surgery than younger women. ${ }^{3,4)}$ Furthermore, women over 70 years of age have a $40 \%$ greater probability of undergoing radical surgery than younger women. Similar findings have been reported world- 
wide. ${ }^{5,6)}$ Nurse support for immunotherapy, breast reconstruction, and chemotherapy is less available for older breast cancer patients than for breast cancer patients who are younger. These trends reflect attitudes influenced by ageism. ${ }^{7)}$ Doctors and nurses reportedly perceive older patients differently from patients who are younger and treat older patients with lower priority. ${ }^{8}$ In clinical studies, many trials excluded participants based solely on an arbitrary upper age limit. ${ }^{9}$

Briggs et al. ${ }^{10)}$ analyzed clinical trials in a teaching hospital over 3 years, reporting that, among 226 relevant trials, 31 used exclusion criteria to remove participants based on age. Most of the remaining trials also contained other exclusion criteria including cognitive function, which further limited participation of older people. These trials excluded older adults because of their seniority and not their inability to give informed consent. ${ }^{11)}$ Furthermore, older adults can buy many drugs over the counter without informational warning that the drugs may not have been tested on people of similar age, owing to age-related exclusion criteria of clinical trials for a number of these drugs. As the numbers of older individuals are increasing, ageism and age discrimination should be prohibited in areas related to public health care.

There are individual differences in the physical changes that occur throughout aging and the speed at which they occur. Simplifying the identification of patients over 65 years of age into a single "elderly" category encourages inaccurate medical judgments and unfair treatment.

To our knowledge, this study is the first to investigate ageism among health care providers and medical students in the Republic of Korea. Korea is a rapidly aging country. The average age of people is increasing faster than that in other developed countries. ${ }^{12)}$ Thus, there is a need to prepare social solutions for issues that aged individuals face across the nation. This study analyzed ageism trends among health care providers and medical students in the Republic of Korea to inform the planning of further studies on this topic.

\section{MATERIALS AND METHODS}

This study was approved by the Ethics Committee of the Catholic University of Korea College of Medicine (No. KC18QESE0532). This survey study investigated a sample of medical students $(\mathrm{n}=90)$, nurses $(\mathrm{n}=114)$, and physicians $(\mathrm{n}=83)$ from one college of medicine and two tertiary university-based hospitals. The survey examined whether health care providers and medical students had completed geriatric classes. The geriatric classes included all undergraduate, post-graduate, and academic lectures. The medical personnel (physicians and nurses) were asked about the percentage of aged patients ( 65 years or over) they had treated in the total number of patients they had treated, Based on the percentage of aged patients that they had treated, the medical personnel were grouped as follow: Group I (0\%-10\%), Group II (11\%$30 \%)$, Group III (31\%-60\%), and Group IV (61\%-100\%).

All gynecology doctors $(n=63)$ were asked about the treatment of uterine myoma. We asked these participants to respond to the following: "A patient with large uterine fibroid showing no increase in size comes to the hospital. The patient is in her 30s, 50s, 70s, and 80s. What treatment would you recommend for her? (a) Myomectomy, (b) Total hysterectomy, or (c) Observation". We wanted to determine if the treatment policy would vary based on patient age for the same medical conditions except for the respective age of the patient.

\section{Instruments}

The instruments used in this study included the Fraboni Scale of Ageism (FSA), Relating to Older People Evaluation (ROPE) questionnaire, Anxiety about Aging Scale (AAS), and Facts on Aging Quiz II.

The FSA ${ }^{13)}$ was used to assess ageism among the participants. The FSA contains 29 questions about ageism, each of which could be scored as 1 (strongly disagree), 2 (disagree), 3 (agree), or 4 (strongly agree). The total FSA score is the sum of scores for all 29 questions, with higher scores indicating greater ageism. To validate the Korean version of the FSA, Kim et al. ${ }^{14)}$ conducted exploratory factor analysis and confirmed a three-factor structure consisting of affective avoidance, discrimination, and stereotyping. This study used the same three-factor structure and total FSA score (Table 1). Eighteen of the 29 questions in Table 1 were included in the three-factor structures; the other eleven were included only in the total score.

The Korean version of the Facts on Aging Quiz II described by Palmore ${ }^{15}$ was used to assess knowledge of aging. This questionnaire contain 25 questions about aging and older persons and is scored as correct or incorrect. The total score for this scale is based on the percentage of correct answers in which higher percentages of correct answers indicate greater knowledge on aging. Previous studies demonstrated a relationship between knowledge of aging and reduced ageism.

The AAS is used to measure a participant's fear of aging. ${ }^{16)} \mathrm{It}$ consists of 20 questions, the answers to which are scored. The four interpretable factors measured in the AAS are fear of older individuals, psychological concerns, physical appearance, and fear of loss. Higher scores indicate more severe anxiety about aging.

The ROPE is a self-reported measure of the frequency and type of ageist behaviors. It is a 20 -item questionnaire that measures per- 
Table 1. Factor structures of the Fraboni Scale of Ageism

\begin{tabular}{lcl}
\hline Structure & Item no. & \multicolumn{1}{c}{ Description } \\
\hline Affective avoidance & 15 & I personally would not want to spend much time with an old person. \\
13 & I would prefer not to go to an open house at a senior's club, if invited. \\
26 & I would prefer not to live with an old person. \\
21 & The company of most old people is quite enjoyable. \\
7 & I don't like it when old people try to make conversation with me. \\
24 & Most old people are interesting, individualistic people. \\
6 & I sometimes avoid eye contact with old people when I see them. \\
20 & It is best that old people live where they won't bother anyone. \\
16 & Most old people should not be allowed to renew their driver's licenses. \\
17 & Old people don't really need to use our community sports facilities. \\
8 & Old people deserve the same rights and freedoms as do other members of our society. \\
22 & It is sad to hear about the plight of the old in our society these days. \\
5 & Many old people just live in the past. \\
10 & Feeling depressed when around old people is probably a common feeling. \\
28 & Old people complain more than other people do. \\
4 & Many old people are not interested in making new friends preferring instead the circle of friends they have had for years. \\
19 & Many old people are happiest when they are with people their own age. \\
3 & Many old people are stingy and hoard their money and possessions.
\end{tabular}

sonal discrimination against older adults using 14 and 6 statements that reflect negative and positive types of ageism, respectively. ${ }^{17)}$ The responses to each question are scored as follows: 0 (never), 1 (sometimes), or 2 (often). The sums of the scores of questions reflecting negative types of ageism (defined as "negative ageistic behavior") and positive types of ageism (defined as "positive ageistic behavior") are calculated. The total score is summed and expressed as the proportion of the highest score possible for either the positive or negative dimensions. Higher scores indicate greater ageist behavior.

\section{RESULTS}

\section{Demographics}

The medical students were significantly younger than the other groups sampled. All nurses in our sample were female. The duration of university and post graduate education was significantly higher for the doctor group than for the other groups. However, the percentage of completed geriatrics classes was significantly higher in the nurse group than those in the other groups.

The percentage of correct answers in the Facts on Aging Quiz II and the FSA total score differed significantly among the three groups (Table 2).

\section{Difference among groups according to their job}

Physicians had more knowledge about aging than other groups, with the highest FSA total scores and lowest ROPE scores. This finding suggests that the doctors hold both knowledge and prejudices regarding aging individuals; The AAS scores were highest in the nurse group (Table 2).

\section{Differences according to the completion of a geriatrics course} We grouped the participants based on whether they had completed a geriatrics course in college. The FSA total score was significantly lower in those who had taken a geriatrics course. However, the group showed significantly higher negative and positive ageist behaviors compared to the groups that had not attended a course (Table 3).

\section{Differences according to the percentages of aged patients treated}

The according to the percentages of aged patients treated (Table 4). The FSA total scores were negatively correlated with the percentage of aged patients treated by health care providers $(r=-0.63$, $\mathrm{p}<0.05)$. Physicians or nurses who treated more older patients appeared to express less ageism. The "avoidance" and "stereotype" subscales of the FSA were both negatively correlated with the percentage of aged patients treated $(r=-0.8$ and $r=-0.7$, respectively, both $\mathrm{p}<0.05$ ). With respect to the ROPE measure, negative and positive ageist behaviors were positively correlated with the percentage of aged patients treated (Fig. 1).

With respect to the AAS, the "fear of old people" subscale was negatively correlated with the percentage of aged patients treated 
Table 2. Demographic information and mean scores on administered measures

\begin{tabular}{|c|c|c|c|}
\hline & Medical students $(\mathrm{n}=90)$ & Nurses $(n=114)$ & Physicians $(\mathrm{n}=83)$ \\
\hline Age, mean (y) & $24.1^{*}$ & 36.6 & 44.2 \\
\hline \multicolumn{4}{|l|}{$\operatorname{Sex}(\%)$} \\
\hline Male & 40 & $0^{*}$ & 26 \\
\hline Female & 50 & 114 & 56 \\
\hline \multicolumn{4}{|l|}{ Educational duration, mean (y) } \\
\hline University*** & 3.6 & 4.6 & 5.7 \\
\hline Graduate school & 1.5 & 1.3 & $3.1^{*}$ \\
\hline Completion of geriatrics class (\%) & 26.6 & 69.2 & 43.3 \\
\hline \multicolumn{4}{|l|}{ Questionnaire score } \\
\hline Facts on aging quiz ${ }^{* * *}$ ( $\%$ of correct responses) & 59.8 & 66.3 & 71.3 \\
\hline FSA total score ${ }^{* * *}$ & 60.8 & 64.8 & 67.3 \\
\hline Avoidance & 15.6 & 14.9 & 16.5 \\
\hline Discrimination & 8.7 & 9.1 & 9.4 \\
\hline Stereotypes & 12.6 & 14.5 & 14.9 \\
\hline Anxiety about Aging Scale & 59.3 & $61.0^{*}$ & 58.2 \\
\hline Fear of losses & 22.4 & 22.7 & 22.1 \\
\hline Fear of old people & 12.7 & 12.4 & 13.1 \\
\hline Physical appearance & 12.7 & 13.2 & 12 \\
\hline Psychological concerns & 7.6 & 7.3 & 7 \\
\hline \multicolumn{4}{|l|}{ ROPE } \\
\hline Negative ageist behavior & $38.9^{*}$ & 27.2 & 26.2 \\
\hline Positive ageist behavior*** & 40.9 & 45.1 & 35.9 \\
\hline
\end{tabular}

FSA, Fraboni Scale of Ageism; ROPE, Relating to Older People Evaluation. ${ }^{*} \mathrm{p}<0.05$, significant difference with the other groups.

${ }_{* * *} \mathrm{p}<0.05$, significant difference between three groups.

Table 3. Differences according to the completion of a geriatrics course

\begin{tabular}{lccc}
\hline \multirow{2}{*}{ Did you take the geriatrics course? } & \multicolumn{2}{c}{ Response } & \multirow{2}{*}{ p-value } \\
\cline { 2 - 3 } & Yes & No & \\
\hline Facts on aging quiz (\% of correct responses) & 66.3 & 65.1 & NS \\
FSA total score & 63.3 & 65.5 & $<0.05$ \\
Avoidance & 15 & 16.3 & $<0.05$ \\
Discrimination & 8.8 & 9.4 & $<0.05$ \\
Stereotypes & 14.1 & 14 & NS \\
Anxiety about aging scale & 59.8 & 59.5 & NS \\
Fear of losses & 18.8 & 18.4 & NS \\
Fear of old people & 12.5 & 13 & $<0.05$ \\
Physical appearance & 12.9 & 12.4 & $<0.05$ \\
Psychological concerns & 7.2 & 7.4 & NS \\
ROPE & & & \\
Negative ageist behavior & 36.5 & 23.3 & $<0.05$ \\
Positive ageist behavior & 45.5 & 35.7 & $<0.05$ \\
\hline
\end{tabular}

FSA, Fraboni Scale of Ageism; ROPE, Relating to Older People Evaluation; NS, not significant.
Table 4. Mean scores on administered measures based on the percentages of aged patients treated

\begin{tabular}{lcccc}
\hline & Group I & Group II & Group III & Group IV \\
\hline $\begin{array}{l}\text { Percentage of aged patients } \\
\text { over 65 years }\end{array}$ & $0-10$ & $<30$ & $<60$ & $<100$ \\
$\begin{array}{l}\text { Facts on aging quiz (\% of cor- } \\
\text { rect responses) }\end{array}$ & 69.7 & 69 & 69 & 69.8 \\
FSA total score & 67.2 & 67.4 & 64 & 64.8 \\
$\quad$ Avoidance & $16.5^{* * *}$ & 16.2 & 14.8 & 14.8 \\
Discrimination & 9.2 & $9.9^{* * *}$ & 8.8 & 9.1 \\
$\quad$ Stereotypes & $14.8^{*}$ & $14.9^{*}$ & 14.5 & 14.5 \\
Anxiety about aging scale & 60.2 & 58.9 & 58.6 & 62 \\
$\quad$ Fear of losses & 6.9 & 7.2 & 6.9 & 7.7 \\
Fear of old people & 19 & 17.9 & 18.4 & 20 \\
Physical appearance & 13.4 & 12.9 & 12.4 & 12.3 \\
$\quad$ Psychological concerns & 12.7 & 12.2 & 12.9 & 13.2 \\
ROPE & & & & \\
$\quad$ Negative ageist behavior & 24.5 & 27.2 & 26.5 & 28.5 \\
Positive ageist behavior & 37.3 & 38.4 & 43.6 & 44.9 \\
\hline
\end{tabular}

FSA, Fraboni Scale of Ageism; ROPE, Relating to Older People Evaluation; ${ }^{*} \mathrm{p}<0.05$, significant difference with group III.

${ }^{* * *} \mathrm{p}<0.05$, significant difference with the other groups. 
A
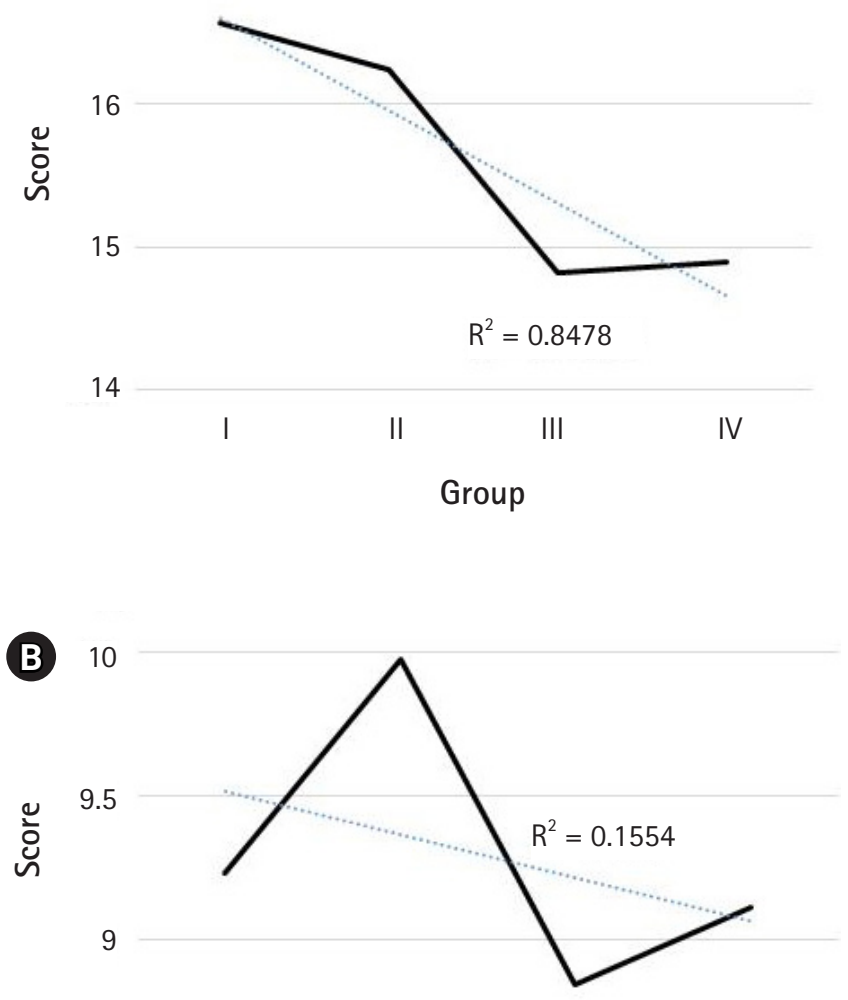

8.5

I II III IV

Group

C

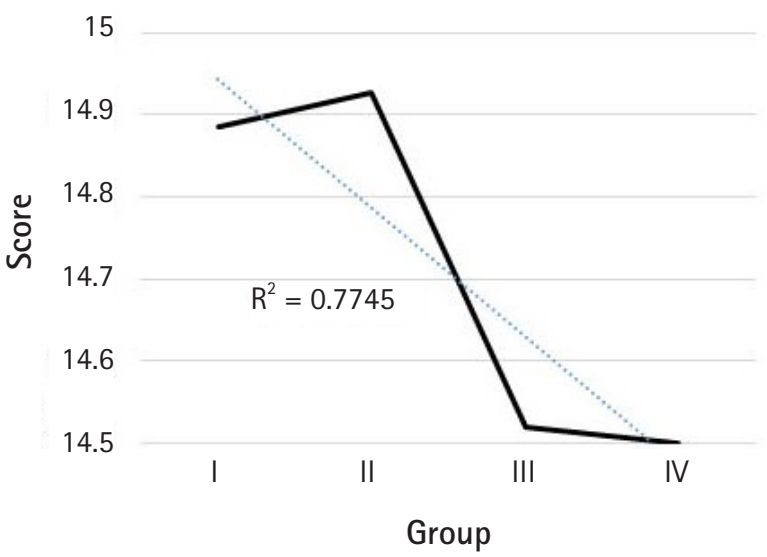

Fig. 1. The Fraboni Scale of Ageism scores and groups according to the percentages of aged patients. (A) Affective avoidance, (B) discrimination, and (C) stereotyping. Affective avoidance and stereotyping showed a negative relationship with the percentages of aged patients, indicating that the more medical providers see older patients, the lower their emotional avoidance or stereotyping. by health care providers. Those treating a large number of aged patients expressed fewer fears and defensive attitudes toward them $(\mathrm{r}=-0.9, \mathrm{p}<0.05)$ (Fig. 2). Physical concerns and psychological concerns were positively correlated with the percentages of aged patients treated by the health care providers. The total AAS score was significantly higher in Group IV, which comprised practitioners who reported that over $70 \%$ of their patients were aged $(\mathrm{p}<0.05)$.

With respect to the ROPE measure, negative and positive ageist behaviors were both positively correlated with the percentage of aged patients treated by the health care providers (Fig. 3).

\section{Choice of treatment based on patient age}

The answers to resort to total hysterectomy for uterine myoma increased with patient age but decreased for patients in their 80s. The answers to resort to uterus preservation, such as myomectomy, decreased with patient age (Fig. 4).

\section{DISCUSSION}

Ageism usually refers to negative attitudes and behavior toward aged adults; however, tax benefits for the aged, public service discounts for the aged, and medical care discounts for older adults demonstrate "ageism for the aged". It may be especially difficult to differentiate positive and negative ageism in health care services and among medical staff because age is usually used as a criterion for treatment indicators such as medication or surgery needs. Individuals above 65 years of age visit hospitals at an average of 12 times a year and precise knowledge of aging among health care providers is an important factor to ensure accuracy in disease diagnosis and sensitivity of efforts to differentiate between normal aging and disease. ${ }^{18)}$ Medical staff should differentiate between treatable diseases among aged individuals and normal physiological decline as a process of aging without prejudice or discrimination.

Prejudice toward older adults among health care providers may also cause over- and under-treatment. Increasing rates of prostate cancer screenings provide an example of over-treatment due to age-related biases. ${ }^{19)}$ Among health care providers, 65\% agreed that "When somebody gets older, he/she feels more pain", 52\% agreed that "When somebody gets older, it is easy to forget", and $14.7 \%$ agreed that "When somebody gets older, he/she is usually depressed" ${ }^{18)}$ These prejudices affect medical staff decision-making. When aged people complain of pain, fatigue, depression, or cognitive impairment, their symptoms are treated as less serious; moreover, these prejudices may interfere with disease diagnosis and prevent health care providers from providing necessary treatments. Health care providers should not assess patients primarily based 
A

21

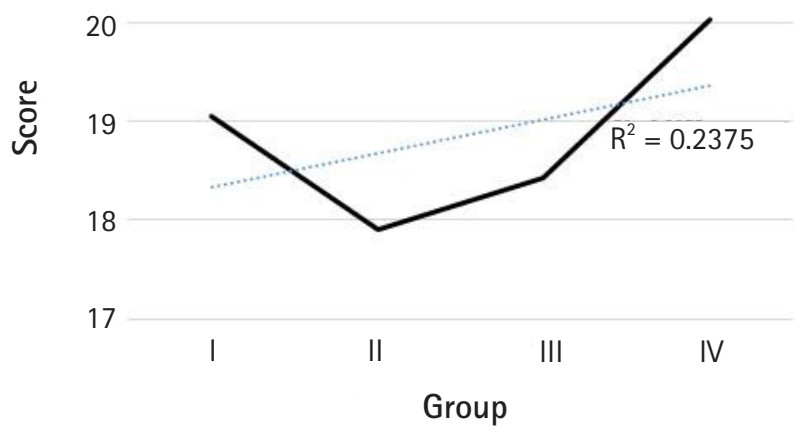

C

14

13.5

ััँ

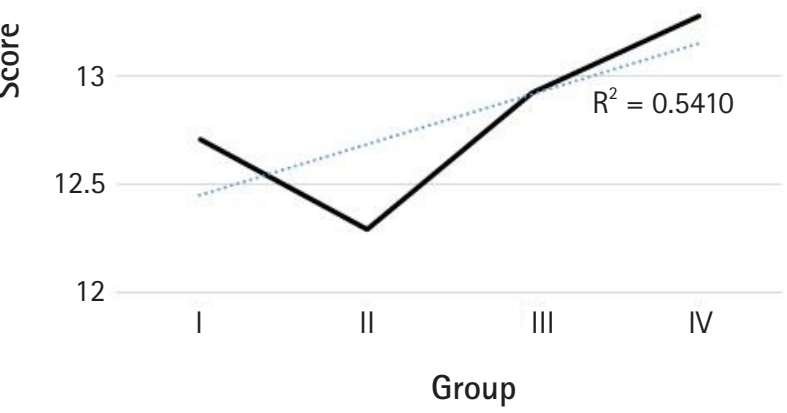

B

\section{4}

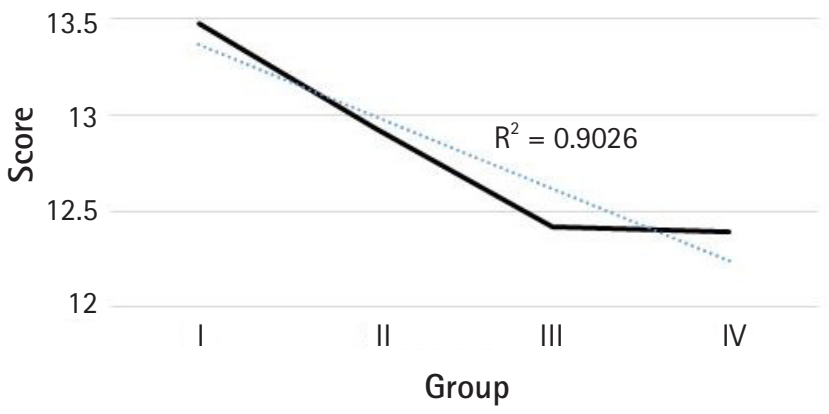

D

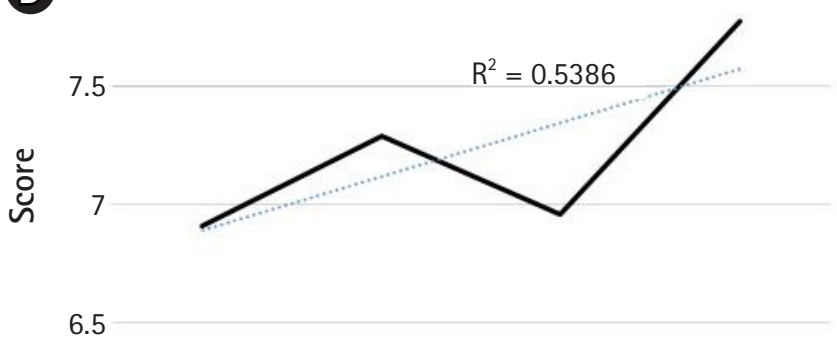

6 । II Group

Fig. 2. The Anxiety of Aging Scale scores and group according to the percentages of aged patients. Fear about physical appearance showed a negative relationship with the percentage of aged patients. Physiological concerns and fear of loss showed a positive relationship with the percentage of aged patients. (A) Fear of older people, (B) physical appearance, (C) physiological concerns, and (D) fear of loses.

on age without considering their physical functioning or accompanying diseases. Patient life expectancy, cognitive ability, functional independence, and nutritional status are important indicators for assessing patient health and recommending adequate treatment.

Schroyen et al. $^{7)}$ reported that immunotherapy, breast reconstruction, and chemotherapy are less commonly administered treatments among aged people and that ageism among nurses in oncology departments affects the rate of reconstructive breast cancer surgeries. The type of treatment that medical staff recommend is influenced by their degree of ageism. ${ }^{20,21)}$ If medical personnel have negative views related to aging, their behavioral engagement with older patients would be consistent with the negative views. ${ }^{7}$

Diseases requiring surgery are increasing in prevalence with age and age itself is not a contraindication to surgery for any disease. ${ }^{22)}$ In a study of 637 aged patients with head and neck cancer, higher age was not associated with increase postoperative complications or mortality. ${ }^{23)}$ Despite these results, heart surgery for patients in their 80 s is not a treatment option $^{24)}$ and reconstructive breast cancer surgery is usually only provided for those under 70 years of age. ${ }^{6}$ Although cardiovascular disease (CVD) is more common in aged individuals, the percentage of patients administered intervention treatments for CVD is affected by their age. Intervention treatments are usually performed more often in younger patients, while medical rather than surgical treatments are administered to aged patients. Furthermore, with advanced age receive minimally adequate treatment after acute myocardial infarction. ${ }^{25,26)}$

Ageism can be divided into conscious ageism and unconscious ageism. ${ }^{27)}$ Conscious ageism is explicit age discrimination, age-specific beliefs, emotions, and behaviors that are enforced in consciousness. Unconscious ageism refers to age-discriminating behaviors, beliefs, and emotions that occur unconsciously. Aged people consistently dissatisfied with their health represents conscious ageism. However, a health care provider not asking an older adult about their sexual life as a consequence of an unconscious belief 
A

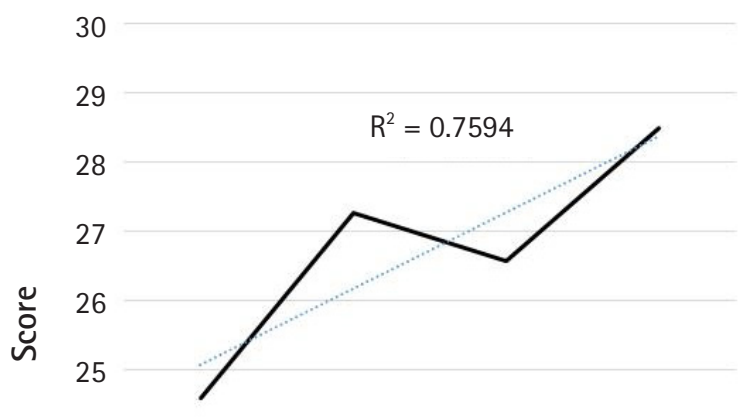

24

23

22

21

20

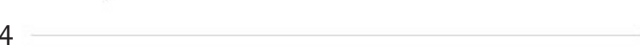

3

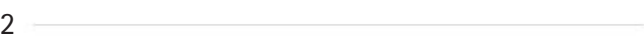

21
I
B

50

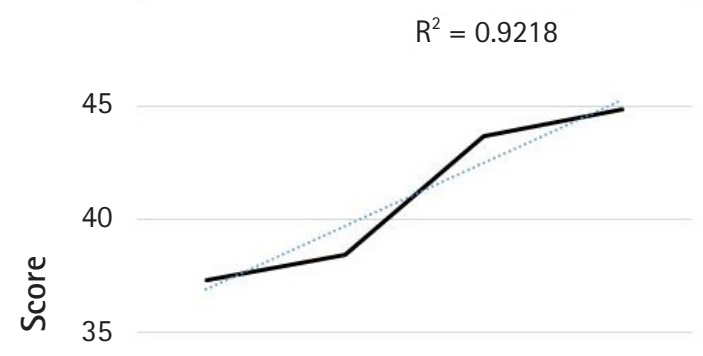

30

25

20

Fig. 3. The Relating to Older People Evaluation scores and groups according to the percentages of aged patients. (A) Negative ageist behavior and (B) positive ageist behavior. Negative and positive ageist behaviors were positively related to the percentages of aged patients, indicating that the more medical providers see older patients, the more ageistic behaviors they evidence.

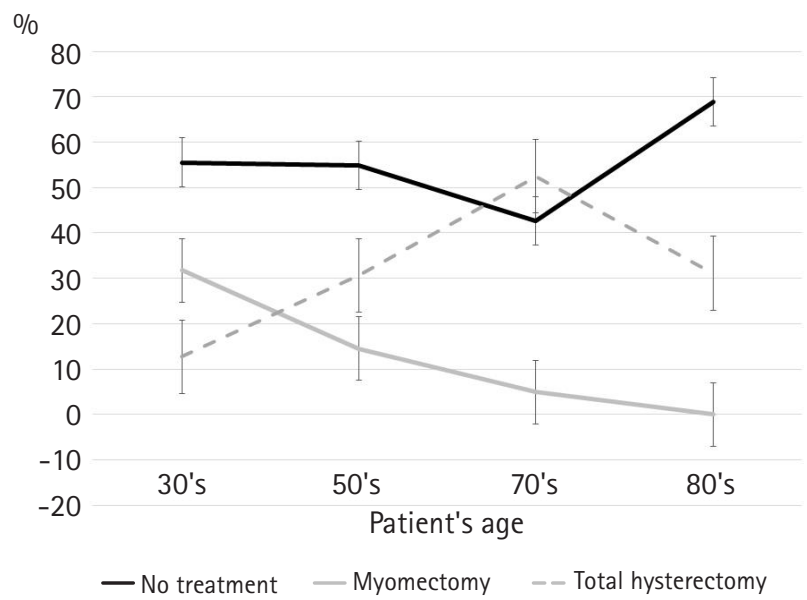

Fig. 4. Choices of treatment methods based on patient age.

that this population is not sexually active constitutes unconscious ageism. Jose et al. reported that many previous publications did not measure unconscious ageism because it required special tools to measure among older patients rather than considering older people as a more general group. ${ }^{27)}$ Unconscious ageism is more harmful to patients than conscious ageism because it can cause health care providers to mistakenly assign specific disease symptoms as normal changes associated with physiological aging. Health care providers often consider older patients to be too old to undergo invasive diagnostic tests. As such, these patients may not receive proper treatment or management due to unconscious ageism in their health care providers. ${ }^{28)}$ Unconscious ageism facilitates prejudiced treatment based on age, eliminating age-related criteria from clinical protocols. Guidelines are not adequate to minimize ageistic treatment. ${ }^{29)}$ Only targeting health care providers with continuous education and promotion of awareness about unconscious ageism can help to reduce this phenomenon.

In this study, the students were the youngest group, followed by nurses and physicians. Students showed the highest FSA score. In previous reports, conclusions regarding the association between ageism and age were unclear. Tuckman and Lorge ${ }^{30)}$ reported higher ageism in parents than in their children; however, a study that included college students and their parents found more favorable responses in parents than the students. Generally, older adults have more positive attitudes toward aging and old age; however, attitudes to aging are not defined by chronological age but may be determined by a more personal experience of aging. ${ }^{31)}$ The effects of age were not completely excluded, which is a limitation of this study.

Our identification of ageism and ageist behavior among a group of doctors differed from the findings of previous reports and other participant groups in this paper. In previous studies, knowledge about aging was negatively correlated with FSA score, while AAS 
was positively correlated with FSA score; ${ }^{11,32,33)}$ contrary to the evidence in the present study. The physicians scored highest for knowledge about aging but also showed the highest FSA score. In a previous study, higher FSA scores typically represented higher consistency with ageist behavior; ${ }^{32,33)}$ however, the physician group showed the lowest ageist behavior scores. In other words, the physicians held the most knowledge and expressed a high level of ageism but did not act ageistically. There are two possible reasons for this finding. The first is that physicians do not act as they are usually thought of in doctor-patient interactions and do not show ageist behaviors toward aged patients. The second is that Asian Confucianism prevents ageist thoughts from manifesting into action, and many Koreans follow traditional Confucian ideas. Confucian values promote positive views of aging and teach younger people to respect, obey, and care for aged individuals. Confucianists do not act as they think (even if they have significant ageist thoughts) because of their social surveillance system. Vauclair et al. ${ }^{34)}$ performed a meta-analysis to compare attitudes toward older people in the east and west; they reported that competence, admiration, and personal attitudes about the aged were more inconsistent in participants from the east.

Previous reports demonstrated that qualified contact with the older adults helped to reduce ageism and anxiety about aging. ${ }^{35)}$ The present study showed lower FSA scores and anxiety about aging among health care providers who treated more patients over 65 years of age. Regarding ageist behavior, the numbers of older patients treated were positively correlated with ageistic behavior. Negative and positive ageist behaviors both increased in proportion with the percentage of the older patients treated. These results indicate that health care providers likely do not recognize their ageist behaviors.

Among all study participants, taking a geriatric class affected the total FSA score. Those that took the course showed lower FSA scores than those who did not. However, ageist behaviors were higher in those that took the class.

The traditional treatment policy for uterine fibroids in gynecology recommends uterine preservation surgery and hysterectomy in younger and older patients, respectively. After menopause, uterine myoma is observed without treatment because it decreases in size after menopause. The results of this study showed that patients in their 70s were recommended hysterectomy under the same medical conditions as women from younger age groups, while those in their 80 s were recommended to undergo observation without treatment. Why not recommend surgery to women in their 80 s? Thus, it is inappropriate to argue that doctors avoid surgery on older patients because of their prejudice toward aged people.

In conclusion, this study investigated age-related bias and preju- diced behaviors among medical students and health care providers in the Republic of Korea. We found that the completion of geriatric classes influenced ageism in medical staff and prospective medical practitioners. We also found ageist behavior in medical staff, even though they see more older patients. These results indicate that continued education of geriatrics and ageism for medical staff and prospective medical personnel could help improve this situation. This study is limited in the sense that it is difficult to apply the results to a broader population of Korean health care providers, as the study was conducted in two tertiary university hospitals. Future research on the effects of ageism education on the behaviors of health care providers should include more institutions.

\section{ACKNOWLEDGMENTS}

\section{CONFLICT OF INTEREST}

The researchers claim no conflicts of interest.

\section{AUTHOR CONTRIBUTIONS}

Conceptualization, HHC; Data curation, JYL, HSY, SRY; Investigation, MWK, SRY; Methodology, HHC, JYL, HSY; Project administration, HHC; Supervision, SRY; Writing original draft, HHC, JYL; Writing review \& editing, HHC.

\section{REFERENCES}

1. Butler RN. Age-ism: another form of bigotry. Gerontologist $1969 ; 9: 243-6$

2. Iversen TN, Larsen L, Solem PE. A conceptual analysis of ageism. Nord Psychol 2009;61:4-22.

3. Mandelblatt JS, Hadley J, Kerner JF, Schulman KA, Gold K, Dunmore-Griffith J, et al. Patterns of breast carcinoma treatment in older women: patient preference and clinical and physical influences. Cancer 2000;89:561-73.

4. Smith GL, Xu Y, Shih YC, Giordano SH, Smith BD, Hunt KK, et al. Breast-conserving surgery in older patients with invasive breast cancer: current patterns of treatment across the United States. J Am Coll Surg 2009;209:425-433. e2.

5. Bates T, Kearins O, Monypenny I, Lagord C, Lawrence G. Clinical outcome data for symptomatic breast cancer: the Breast Cancer Clinical Outcome Measures (BCCOM) Project. Br J Cancer 2009; 101:395-402.

6. Di Rosa M, Chiatti C, Rimland JM, Capasso M, Scandali VM, Prospero E, et al. Ageism and surgical treatment of breast cancer in Italian hospitals. Aging Clin Exp Res 2018;30:139-44.

7. Schroyen S, Missotten P, Jerusalem G, Gilles C, Adam S. Ageism and caring attitudes among nurses in oncology. Int Psychogeriatr 
2016;28:749-57.

8. Skirbekk H, Nortvedt P. Inadequate treatment for elderly patients: professional norms and tight budgets could cause "ageism" in hospitals. Health Care Anal 2014;22:192-201.

9. Kim SW, Jung HW, Park M, Chung JY, Lee KW, Kim JH, et al. Current state and future improvement of the elderly participation in clinical trials. J Korean Geriat Soc 2014;18:122-35.

10. Briggs R, Robinson S, O'Neill D. Ageism and clinical research. Ir Med J 2012;105:311-2.

11. Godlovitch G. Age discrimination in trials and treatment: old dogs and new tricks. Monash Bioeth Rev 2003;22:66-77.

12. He W, Goodkind D, Kowal P. An aging world: 2015 international population reports. Washington, DC: US Department of Commerce; 2016.

13. Fraboni M, Saltstone R, Hughes S. The Fraboni Scale of Ageism (FSA): an attempt at a more precise measure of ageism. Can J Aging 1990;9:56-66.

14. Kim JY, Kim MH, Min KH. Validation of the Korean version of the Fraboni Ageism Scale (FSA): a study of Korean university students. Korean J Soc Pers Psychol 2012;26:89-106.

15. Palmore EB. The facts on aging quiz: part two. Gerontologist 1981;21:431-7.

16. Lasher KP, Faulkender PJ. Measurement of aging anxiety: development of the Anxiety about Aging Scale. Int J Aging Hum Dev 1993;37:247-59.

17. Cherry KE, Palmore E. Relating to older people evaluation (ROPE): a measure of self-reported ageism. Educ Gerontol 2008;34:849-61.

18. Davis MM, Bond LA, Howard A, Sarkisian CA. Primary care clinician expectations regarding aging. Gerontologist 2011;51:85666.

19. Berwick DM, Hackbarth AD. Eliminating waste in US health care. JAMA 2012;307:1513-6.

20. Madan AK, Aliabadi-Wahle S, Beech DJ. Ageism in medical students' treatment recommendations: the example of breast-conserving procedures. Acad Med 2001;76:282-4.

21. Protiere C, Viens P, Rousseau F, Moatti JP. Prescribers' attitudes toward elderly breast cancer patients. Discrimination or empathy? Crit Rev Oncol Hematol 2010;75:138-50.

22. Katlic MR. Consider surgery for elderly patients. CMAJ 2010;182:1403-4.

23. Wu Y, Zhang B, Huang Z, Ruan Y, Huang Z. Study of surgical treatment for elderly patients with head and neck cancer. Int J Oral Maxillofac Surg 2018;47:824-9.

24. Mirabel M, Iung B, Baron G, Messika-Zeitoun D, Detaint D, Vanoverschelde JL, et al. What are the characteristics of patients with severe, symptomatic, mitral regurgitation who are denied surgery? Eur Heart J 2007;28:1358-65.

25. McLaughlin TJ, Soumerai SB, Willison DJ, Gurwitz JH, Borbas C, Guadagnoli E, et al. Adherence to national guidelines for drug treatment of suspected acute myocardial infarction: evidence for undertreatment in women and the elderly. Arch Intern Med 1996; 156:799-805.

26. Black N, Langham S, Petticrew M. Trends in the age and sex of patients undergoing coronary revascularisation in the United Kingdom 1987-93. Br Heart J 1994;72:317-20.

27. Sao Jose JM, Amado CA, Ilinca S, Buttigieg SC, Taghizadeh Larsson A. Ageism in health care: a systematic review of operational definitions and inductive conceptualizations. Gerontologist 2019;59:e98-e108.

28. Levy BR, Banaji MR. Implicit aegism. In: Nelson TD, editors. Ageism: stereotyping and prejudice against older persons. Cambridge, MA: MIT Press; 2002.p. 49-75.

29. Clarke A. Ageism and age discrimination in primary and community health care in the United Kingdom. London: Centre for Policy on Ageing; 2009.

30. Tuckman J, Lorge I. Attitudes toward old people. J Soc Psychol 1953;37:249-60.

31. Diehl MK, Wahl HW. Awareness of age-related change: examination of a (mostly) unexplored concept. J Gerontol B Psychol Sci Soc Sci 2010;65B:340-50.

32. Holtzman JM, Beck JD, Ettinger RL. Cognitive knowledge and attitudes toward the aged of dental and medical students. Educ Gerontol 1981;6:195-207.

33. Miller RB, Dodder RA. An empirical analysis of Palmore's facts on aging quiz and the miller-dodder revision. Sociol Spectr 1984;4(1):53-69.

34. Vauclair CM, Hanke K, Huang LL, Abrams D. Are Asian cultures really less ageist than Western ones? It depends on the questions asked. Int J Psychol 2017;52:136-44.

35. Levy SR. Toward reducing ageism: PEACE (Positive Education about Aging and Contact Experiences) model. Gerontologist 2018;58:226-32. 